Revista de Ciencias Sociales - Número 66 (2015) - Páginas 63-101

Metodología del derecho privado a la luz de las convenciones, tratados...

\title{
METODOLOGÍA DEL DERECHO PRIVADO A LA LUZ DE LAS CONVENCIONES, TRATADOS DE DERECHO HUMANOS, LA CONSTITUCIÓN Y LA PROTECCIÓN DE LOS DERECHOS DE LOS CONSUMIDORES*
}

\author{
METHODOLOGY OF PRIVATE LAW IN THE LIGHT \\ OF THE CONVENTIONS, TREATIES ON HUMAN \\ RIGHTS, THE CONSTITUTION AND THE \\ PROTECTION OF CONSUMER RIGHTS
}

\author{
JORGE BARAONA GONZÁLEZ** \\ Universidad de los Andes (Chile) \\ jbaraona@uandes.cl
}

\section{Resumen}

El presente ensayo presenta algunos factores que inciden en la metodología del derecho privado, entendida ésta como el empeño metódico para solucionar problemas en derecho privado, en donde los criterios de justicia

\footnotetext{
* Versión escrita y revisada de la conferencia para inaugurar el año académico 2015 del Posgrado de la Escuela de Derecho de la Universidad de Valparaíso, dictada el 23 de marzo de 2015.
}
* Doctor en Derecho, profesor de Derecho Civil. Artículo recibido el 21 de abril de 2015 y aceptado el 28 de mayo de 2015.


conmutativa para el derecho contractual, y el de justicia correctiva para el derecho de daños, son esenciales. Se explica que el sistema de fuentes es hoy más abierto y que los principios se incorporan decisivamente, como también la jurisprudencia. En una segunda parte el autor revisa el impacto que una metodología del derecho privado, así descrita, recibe de la doctrina de los derechos fundamentales, lo que obliga a aplicarlos en una relación de derecho privado. Se revisa también la influencia del derecho del consumidor en el derecho privado común.

\section{Palabras clave}

Metodología, derecho privado, derechos fundamentales, consumidor.

\section{Abstract}

This essay presents some factors indexed on the methodology of private law, understood as the methodical effort to solve problems in private law, where the criteria of commutative justice, for contract law, and corrective justice, for the right damage, are essentials. It explains that the system uses more open sources and that the principles are incorporated decisively, as well as jurisprudence. In a second part, the author reviews the impact of private law methodology, thus described, received by the fundamental rights doctrine, forcing apply in private law relationship. The influence of consumer law in private common law is reviewed.

\section{Keywords}

Methodology, private law, fundamental rights, consumer.

\section{Introducción: la noción de metodología del derecho y caracterización del derecho privado}

Voy a reflexionar brevemente, y en un marco muy general, sobre la metodología del derecho privado $^{1}$ y la manera que está hoy impactada

1. El Libro que me sirve de principal apoyo es el de LARENZ, Karl: Metodología de la Ciencia del Derecho, Ariel, Barcelona, 1994; puede ser muy útil también VALLET DE GOYTISOLO, Juan Berchmans: Metodología de la determinación del Derecho, Editorial Centro de Estudios Ramón Areces, Madrid, 1994. Como ciencia es SAVIGNY, Friedrich: Metodología Jurídica, (traducción no indicada) Valletta Ediciones, Buenos Aires, 2004, quien la funda.

Facultad de Derecho y Ciencias Sociales - Universidad de Valparaíso - Chile 
por los tratados sobre derechos humanos, la misma Constitución y el derecho del consumo.

\subsection{Noción de metodología}

Vamos a entender por metodología del Derecho a la vía metódica que se propone determinar el derecho aplicable o, si se quiere, indagar por la solución jurídica a un problema concreto que se enfrenta y que aparece en el marco de una relación jurídica determinada.

Se trata de investigar "aguas abajo" de la Filosofía del Derecho, disciplina que se pregunta por los fundamentos del Derecho, por su justificación última, en diversas variantes epistemológicas².

La base con que trabaja la metodología es la dogmática, de dogma, es decir algo indudable 3 . Aunque con el tiempo el derecho se ha hecho mucho más flexible ${ }^{4}$ en el sentido que más que la verdad lo que se propone, lo que muchos pretenden es ofrecer soluciones plausibles; por sobre la proposición misma, lo que se espera es que el método que se emplea para formularla sea aceptado por la comunidad científica a la que se destina y por lo mismo sus resultados puedan ser verificables, porque puede ser confirmada o refutada. Su objetivo, entonces, es formular afirmaciones criticables 5 .

2. Sobre el Derecho como objeto del conocimiento, MARTÍNEZ DORAL, José

María: La estructura del conocimiento jurídico, Universidad de Navarra, Pamplona, 1963, pág. 157, quien distingue en el derecho un nivel filosófico, un nivel propiamente científico y un nivel práctico, de actividad, en el que se ejerce propiamente el juicio prudencial.

3. Como lo explica WIEACKER, Franz: Historia Moderna del Derecho Privado de la Edad Moderna, Comares, (traducción del alemán de Francisco Fernández Jardón), Granada, 2002, pág. 43, con el nacimiento de la ciencia del derecho romano "se produjo un sistema doctrinal autoritario de dogmas sin contradicción alguna y de verdad absoluta...”.

4. ZAGREBELSKY, Gustavo: El derecho dúctil. Ley, derechos, justicia, (traducción de Marina Gascón, 5a edición), Editorial Trotta, Madrid, 2003.

5. BERNASCONI, Andrés: "El carácter científico de la Dogmática”. En: Revista de Derecho (Valdivia), XX, N 1, Junio de 2007, págs. 9-37.

Revista de Ciencias Sociales - Número 66 (2015) - Universidad de Valparáíso - ISSN 0716-7725-Valparaíso, Chile 
Los instrumentos que usa son: el sistema normativo o de fuentes; la técnica investigativa, para dar con el aparato instrumental-crítico (material doctrinal y jurisprudencial, básicamente), para detectar los problemas que existen, formular las preguntas correctas, e intuir hipotéticamente las soluciones posibles; el raciocinio y la argumentación a que se recurre, son propios de la ciencia jurídica ${ }^{6}$, sobre lo cual no hay mayor unidad científica.

Lo que se busca en un trabajo dogmático es dar con una propuesta específica sobre un tema determinado; algunos creen que bajo un prisma sistemático ${ }^{7}$, aunque se ha de cuidar de formular criterios excesivamente rígidos, por seguir criterios coherentes.

\subsection{La caracterización del derecho privado}

Para caracterizar el derecho privado ${ }^{8}$, lo clave está en diferenciar el ámbito público del privado y en ambos detectar el interés público o colectivo, para separarlo del interés privado o particular; por otra parte, es útil distinguir entre entes con personalidad jurídica de derecho público de los que tienen personalidad privada; por último, es importante detectar el uso de potestades públicas.

Así, el derecho privado regula las relaciones jurídicas entre privados o particulares, o con personas jurídicas de derecho público que no ejercen potestades públicas. La protección de intereses en el derecho privado, como regla, queda entregada a los propios titulares y ello sin perjuicio de los límites históricos del orden público y las buenas

6. VERGARA BLANCO, Alejandro: "Sistema y Autonomía de las disciplinas jurídicas. Teoría y Técnica de los Núcleos Dogmáticos”, en Revista Chilena de Derecho, Vol 41, N³, 2014, p. 962; También en ALEXY, Robert: Robert, El concepto y la validez Del Derecho, (traducción J. Seña de la edición alemana de 1992), segunda edición, Barcelona, 2004, págs. 68 y ss.

7. VERGARA BLANCO, Alejandro: Ibíd., pág. 969. "El sistema es orden y unidad".

8. Para un estudio de la distinción, VERGARA BLANCO, Alejandro: "La Summa Divisio Iuris Público/Privado de las disciplinas jurídicas”. En: Revista de Derecho (Universidad Católica del Norte), Año 17, No 1, (2010), págs. 117 y ss.

Facultad de Derecho y Ciencias Sociales - Universidad de Valparaíso - Chile 
costumbres, que permiten la coordinación de los intereses privados entre ellos mismos y con el interés público ${ }^{9}$, por el cual vela la autoridad.

Para el profesor Enrique Barros el derecho privado "es un orden normativo orientado por un concepto no instrumental de lo que es correcto, que, expresado en términos kantianos, constituye 'el conjunto esencial (Inbegriff) de las condiciones bajo las cuales el arbitrio de uno puede ser conjugado con el arbitrio del otro según una luz general de la libertad"” 10 .

La clave está, me parece, en concebir su objeto de estudio acentuando la relación entre personas — que es lo propio del Derechopero de carácter privado o entre particulares. Tiene un sustrato normativo propio, y aquí detectamos un aspecto esencial, pues, el derecho pertenece al orden normativo, o del deber ser, pero su característica más saliente es que tiene un carácter coercitivo u obligatorio.

El sistema jurídico como conjunto se propone "ordenar" esta relación, que en sí misma directamente no es funcional al interés público, sino los intereses de quienes están involucrados en ella, que deben coordinarse con aquél. Por ello, indirectamente, existe un interés público en protegerla.

En la base de la relación de derecho privado aparece una relación de justicia ${ }^{11}$, que en los contratos es de tipo conmutativa. De aquí aparece

9. Estoy bien consciente que la idea de interés público puede resultar para algunos difícil de concebir, pero si se habla de interés privado y no de interés a secas, es porque debe existir algún tipo de interés que no sea privado. Por ello, prefiero poner el acento en la idea de privacidad, en el sentido de que quien formula y quien protege es un particular.

10. BARROS, Enrique: “Lo público y lo privado en el Derecho”, versión revisada y completada del discurso de incorporación del autor a la Academia de Ciencias Políticas y Morales. En Estudios Públicos, 81, (2001), págs. 5-37. GORDLEY, James: The philosophical Origins of Modern Contract Doctrine, Clarendon Law Series, reimpresión, Clarendon Press, Oxford, 1991, passim, quien formula un juicio histórico afirmando que el verdadero fundamento de los contratos está en la explicación aristotélico-tomista del ejercicio de las virtudes la justicia conmutativa, o de la liberalidad para los contratos gratuitos.

11. Sobre este tema véase WEINRIB, Ernest: The idea of Private Law, Oxford University Press, 2012.

Revista de Ciencias Sociales - Número 66 (2014) - Universidad de Valparáíso - ISSN 0716-7725-Valparáiso, Chile 
el principio básico de la regulación contractual: el sinalagma o equilibrio prestacional. También algunas relaciones derivadas del injusto enriquecimiento (los cuasicontratos), se rigen por este tipo de justicia. Además, debe recurrirse a la denominada "justicia correctiva”, según el término aristotélico, cuya función es restablecer un daño causado, operando en la responsabilidad por daños y en ciertos supuestos de enriquecimiento injusto.

En las relaciones jurídico-reales, el carácter privado del derecho exige con mayor nitidez la institucionalidad pública, porque en ella reposan instituciones que reconocen tales derechos, los amparan y les dan protección: es el caso de los derechos reales, que son reconocidos por la ley y muchos están protegidos en sistemas registrales. Aquí el derecho privado es también instrumento de satisfacción de intereses personales, egoístas si se quiere, pero, no hay duda, se nutre de la institucionalidad pública para hacer efectiva su operación. La ley los crea y configura, en términos de definir los derechos o facultades derivadas de su ejercicio y que hoy, por mandato constitucional, sólo pueden provenir de disposiciones que hagan operativa su función social (cfr. art. $19 \mathrm{~N}^{\circ} 24$ de la CPR). La teoría o principio del abuso del derecho nace justamente como una manera de controlar el ejercicio de este tipo de derechos. La base de su protección y de las relaciones que de ellos nacen, es el de la justicia correctiva, porque la exigencia del sujeto pasivo que la ley le impone es de reconocer y respetar el derecho ajeno, por lo mismo no causarle daño.

Es interesante tener presente que, conforme está configurado en nuestra protección el derecho de propiedad en el artículo $19 \mathrm{~N}^{\circ} 24$ de la Carta de 1980, tienen protección dominical incluso los derechos personales ${ }^{12}$.

No podemos perder de vista que el derecho privado tiene contenido histórico, porque sus fuentes pueden rastrearse hasta el derecho romano. Por ello, una adecuada metodología del derecho privado no puede prescindir de esta información y rastreo histórico ${ }^{13}$.

12. Sobre el tema, GUZMÁN BRITO, Alejandro: Las cosas incorporales en la doctrina y el derecho positivo chileno, segunda edición actualizada, Editorial Jurídica de Chile Santiago, 2006.

13. Es clásico el trabajo de WIEACKER, cit., passim; una precisa historia del derecho privado desde la óptica de los juristas, y con sentido crítico, puede

Facultad de Derecho y Ciencias Sociales - Universidad de Valparaíso - Chile 
Tampoco debe obviarse como clave metodológica, la necesidad de comparación e integración de los diversos sistemas nacionales ${ }^{14}$, para iluminar las propias instituciones o para encontrar estructuras similares en todas ellas. El método del derecho comparado, como los ejercicios de armonización, tanto europeos ${ }^{15}$, como los incipientemente comienzan nuestro continente ${ }^{16}$, cobran peculiar relevancia.

No debe dejar de mencionarse que cualquier empeño metodológico supone una opción metódica. Sabemos que iusnaturalismo o iuspositivismo, han sido las clásicas del derecho moderno; pero hoy encontramos muchas alternativas metodológicas, como el realismo, el normativismo, el voluntarismo político o de cambio social, el economicismo, en sus diversas variantes, los sociologismos de distinto cuño, el funcionalismo, liberalismo, marxismo, etc.

Por ello, actualmente son auxilios imprescindibles a cualquier método en derecho privado, ciencias como la economía, sociología,

verse en GORDLEY, James: The jurists, Oxford, 2013; otro impresionante trabajo de síntesis histórica del derecho de las obligaciones, es el que hace ZIMMERMANN, Reinhard: The law of Obligations, Roman Foundations of The Civilian Tradition, Clarendon Paperbacks, Oxford University Press, 1996.

14. Cfr. HESSELINK, Martijn: "AS European Legal Method? On European Private Law and Scientific Method". En: European Law Journal, Vol $15 \mathrm{~N}^{\circ} 1$, 2009, págs. 20-45.

15. Son muchas la iniciativas, como el que dio lugar al denominado Principios del Derecho Europeo de los Contratos, preparados por la Comisión Lando, que debe su nombre al profesor sueco Ole Lando, quien la presidió, y que en un proceso de maduración, a instancias del grupo de estudio encabezado por el profesor Christian V. Bar, derivó en el denominado Proyecto del Marco Común de Referencia, con el impulso de la Unión Europea; otra iniciativa es el Código Europeo de Contratos, preparado por Grupo de Pavía, presidido por el profesor Giuseppe GANDOLDI; o los Principios de Derecho Europeo de la Responsabilidad Civil.

16. Es el caso del denominado Proyecto sobre Los Principios Latinoamericanos de Derechos de los Contratos, que en nuestro país encabezan profesores de la Facultad de Derecho de la Universidad Diego Portales, y que ya ha publicado sus primeras propuestas (http://fundacionfueyo.udp.cl/proyecto-sobre-principioslatinoamericanos-de-derecho-de-los-contratos).

Revista de Ciencias Sociales - Número 66 (2015) - Universidad de Valparáíso - ISSN 0716-7725-Valparaíso, Chile 
antropología, la misma política, que han ejercido tanta influencia, a punto tal que tenemos escuelas metodológicas unidimensionales; como el análisis económico del derecho, la escuela marxista del derecho, etc. Con todo, la mejor configuración teórica de los derechos puede resultar ineficaz, si no se acompaña de un marco operativo adecuado para ejercerlos, es decir que tales derechos sean efectivamente tuteados ${ }^{17}$. De aquí que también al derecho privado le sea muy cara la necesidad de un ámbito institucional y judicial, eficiente y efectivo, que ofrezca herramientas adecuadas al servicio del interés privado.

\section{Las fuentes del Derecho}

El primer aspecto metodológico, y que es esencial, es determinar las fuentes del derecho.

Lo clásico es responder conforme con lo que nuestro CC prescribe como fuentes del derecho: ley y la costumbre (el art $2^{\circ}$ del Cc sólo se permite la costumbre secundum legem y en el C. de Comercio se agrega la costumbre praeter legem); se excluye a la jurisprudencia; a los principios generales y la equidad natural se recurre únicamente en silencio de la ley (art. 24 CC y $170 \mathrm{n}^{\circ} 5$ del CPC).

Pero hoy la cuestión es más compleja, porque no puede dudarse de la necesidad de incluir a los principios generales del derecho ${ }^{18}$, y no sólo en su función integradora, sino también interpretativa. Con todo, no hay coincidencia acerca de lo que debe entenderse por principios generales del derecho, en el sentido de cómo se reconocen y cuáles son ellos.

Como se sabe, un evidente acercamiento entre iuspositivismo y ius naturalismo (de no positivistas se hablará), se produce a partir de

17. Por todos DI MAJO, Adolfo: La tutela civili dei diritti, 3, Giuffrrè, Milano, 2003.

18. Cfr. ALCALDE RODRÍGUEZ, Enrique: Los Principios Generales del Derecho, Ediciones PUC, Santiago, 2003; es clásica la obra de DEL VECCHIO, Giorgio: Los principios generales del Derecho, (prólogo de Felipe Clemente de Diego y traducción de Juan Osorio Morales), Lima, 2006.

Facultad de Derecho y Ciencias Sociales - Universidad de Valparaíso - Chile 
las concepciones de ALEXY ${ }^{19}$ y DwORKIN ${ }^{20}$ sobre el Derecho, al incorporar a los principios de derecho como para de sus fuentes. Tanto así, que el mismo HaRT tuvo que reconocer que en su primera edición de su famoso The Concept of Law, en 1961, le prestó poca atención a los principios; en su posterior edición, refutando a DwORKIN, acepta que los principios pueden ser fuentes de derecho, aunque insiste que sólo pueden reconocerse desde una norma de reconocimiento ${ }^{21}$.

Por otra parte, la doctrina jurisprudencial, sea por su propio impulso, o por efecto de la actuación de la doctrina y de los abogados que intervienen ante los Tribunales, se ha convertido de hecho en fuente del Derecho, pues, los Tribunales inferiores tienden a seguir cada día más las doctrinas que proponen los Tribunales superiores, particularmente la de la Corte Suprema. La misma modificación a las normas sobre recursos de casación, en la década de los noventa en nuestro país, se encamina en esta línea ${ }^{22}$.

Por su parte, recursos como el de unificación de jurisprudencia en materia laboral, demuestra que esta fuente ha sido valorada por el propio legislador, en homenaje al principio de igualdad ante la ley.

\section{Principios, reglas, conceptos jurídicos indeterminados o estándares, y cláusulas generales en el derecho privado}

\subsection{Principios}

El reconocimiento de los principios generales del Derecho como fuente del sistema, ha llevado a los teóricos a distinguir entre principios generales y principios especiales, según el área o sistema de aplicación

19. ALEXY, Robert: ob. cit., pp. 159 y ss.

20. DWORKIN, Ronald: El imperio de la justicia, Gedisa, Barcelona, 1988.

21. HART, H.L.A., The concept of law, prólogo a la segunda edición, Oxford University Press, London, 1994 (hay traducción al castellano de este prólogo en Estudios Públicos, N 65, 1997, págs. 226-263).

22. Cfr. ROMERO SEGUEL, Alejandro: La jurisprudencia de los tribunales como fuente del derecho. Una perspectiva procesal, Editorial Jurídica de Chile, Santiago, 2004.

Revista de Ciencias Sociales - Número 66 (2015) - Universidad de Valparáíso - ISSN 0716-7725-Valparáiso, Chile 
cuya función es múltiple, entre ellas destacamos: de aplicación; de interpretación; de ponderación de normas.

- Entre los más importantes principios en el derecho contractual ${ }^{23}$ destacamos: buena fe; de la confianza; de enriquecimiento sin causa; de la responsabilidad; de la autonomía de la voluntad; relatividad contractual; de colaboración contractual; favor negotii; interpretación pro homine; del abuso de derecho.

- En derecho inmobiliario y registral ${ }^{24}$ : fe pública registral; de legalidad registral; tipicidad; legitimación registral; etc.

- En derecho de familia ${ }^{25}$ : interés superior del niño; protección de la familia matrimonial; protección al cónyuge débil; protección del matrimonio, entre otros.

\subsection{Reglas}

Las reglas están en un nivel más operativo, porque son exigencias normativas de aplicación mucho más precisas, que tienden a exigir al juez su aplicación, bajo un criterios binario, y en supuestos fácticonormativo, determinados. Muchas veces están recogidas en aforismos o apotegmas, que tienen lar data. Algunos importantes en el derecho privado $^{26}$ : nemo auditur propriam turpitudinem allegans; venire contra factum proprium ${ }^{27}$; deber de mitigar daños ${ }^{28}$. Estos principios y reglas hoy están en la base de muchas decisiones judiciales.

23. Vid. LÓPEZ SANTA MARÍA, Jorge: Los Contratos, Parte General, (quinta edición actualizada por Fabián Elorriaga De Bonis), Abeledo Perrot-Legal Publishing, Santiago, 2011, págs. 191-360.

24. http://derechonotarialyregistral.weebly.com/principios-registrales.html

25. Cfr. BARCIA LEHMANN, Rodrigo: Fundamentos Del Derecho de Familia y de la Infancia, Punto Lex-Thomson Reuters, Santiago, 2011, Págs. 23-25.

26. DOMINGO, Rafael y RODRÍGUEZ-ANTOLÍN, Beatriz, Aforismos Jurídicos, Aranzadi, Pamplona, 2000.

27. Cfr. CORRAL, Hernán et Al.: Venire contra factum proprium. Escritos sobre la fundamentación, alcance y límites de la doctrina de los actos propios. En Cuadernos de Extensión (U. de los Andes ), 18, 2010, (Hernán Corral editor).

28. Cfr. SAN MARTÍN, Lilian: La carga del perjudicado de evitar o mitigar el daño, Universidad Externado de Colombia, Bogotá, 2012.

Facultad de Derecho y Ciencias Sociales - Universidad de Valparaíso - Chile 


\subsection{Conceptos jurídicos indeterminados (normas estándar)}

Un aspecto interesante es distinguir los principios de derecho y las reglas, de otras figuras como las denominadas cláusulas generales ${ }^{29}$, normas estándar o preceptos indeterminados.

La idea de concepto jurídico estándar o indeterminado apunta a descripciones normativas muy abstractas, que obligan al juez a calificar un determinado hecho y atribuirle consecuencias jurídicas. Así, las nociones del Código Civil tales como cumplimiento, incumplimiento, responsabilidad, culpa/diligencia, dolo, buena o mala fe subjetiva, orden público, buenas costumbres, bien, beneficio, daño, perjuicio, negocio, utilidad, beneficencia, gravamen, oneroso, interés, operación, servicio, caso fortuito, necesidad imperiosa, etc. Estas nociones confieren más espacio al operador, particularmente al juez, para su concreción, por lo que hace más importante la argumentación misma que el hecho puro de su aplicación.

Hay veces que una misma noción puede jugar una doble función. Por ejemplo, la buena fe puede ser tratada como principio general, en su faz de creación de derecho, de acuerdo con lo que dispone el artículo 1546 del CC. Pero también puede aparecer como un concepto estándar o indeterminado o cláusula general, para los efectos de describir un estado psicológico. Es el caso de la buena fe posesoria, o la buena fe que requiere el adquirente, conforme con lo que dispone el artículo 1490 del Código Civil.

\subsection{Cláusulas generales}

Las cláusulas generales en el derecho continental son indiciarias de normas muy abiertas en su formulación, que permiten encuadrar muchos supuestos de aplicación normativa. Tal es el caso de la clásica regla del daño que contiene el artículo 2314 del CC, que nuestro Código trajo formalmente del derecho francés, apartándose de la tradición

29. Cfr. GRUNDMANN, Stefan et Al.: General Clause and Standars im European

Contract Law: Edited by Stefan Grundmann and Denis Mazeaud, Kluwer Law, International, The Hague, 2006.

Revista de Ciencias Sociales - Número 66 (2015) - Universidad de Valparáíso - ISSN 0716-7725-Valparáiso, Chile 
romana, aunque que ya venía siendo también estudiado como un sistema con cláusula general por los comentadores de las Partidas ${ }^{30}$. Es una norma tan abierta, que permite encajar en ella toda conducta dañosa de la cual se pretende hacer derivar responsabilidad. La figura de la nulidad en los actos y contratos, regulada en los arts. 1681 y ss. del CC, con una mayor o menor concreción, también puede ser considera una cláusula general.

\section{Los criterios de selección normativa, tanto en el tiempo como en el espacio}

Una vez que tenemos organizado un sistema de fuentes, debemos escoger las normas que aplicaremos al caso, para ello, aparte de los criterios generales sobre validez y eficacia de la ley, quiero concentrarme, en cuatro:

a) La norma superior prima sobre la ley inferior. Este criterio en su aplicación requiere de un procedimiento refinado ${ }^{31}$ (cfr, arts. $6^{\circ}$ y $7^{\circ}$ de la Constitución).

El control de convencionalidad permite purgar normas legales que eventualmente vayan en contra de tratados de derechos humanos.

b) La regla de la especialidad, que predica que la norma especial debe primar sobre la general: artículos $4^{\circ}$ y 13 del CC.

Este es un principio de aplicación general, pero no es fácil especialmente cuando se tiene problemas que son de carácter general, pero que se manifiestan en un área específica.

Temas como la nulidad de los actos y contratos, la responsabilidad civil, la regulación de las sociedades civiles,

30. BARRIENTOS GRANDÓN, Javier: “de la presunción general de culpa por el hecho propio”. A propósito de los artículos 2314 y 2329 de nuestro “Código Civil imaginario'. En: Revista Chilena de Derecho Privado, ${ }^{\circ} 13$, diciembre (2009), págs. 9-94.

31. Cfr. SILVA IRARRÁZAVAL, Luis Alejandro: El control de constitucionalidad de los actos administrativos legales, Legal Publishing, Santiago, 2009.

Facultad de Derecho y Ciencias Sociales - Universidad de Valparaíso - Chile 
la prescripción extintiva, suelen generar problemas de aplicación de normas.

El CC, en cuanto es derecho común y por lo omnicomprensiva en su regulación, podría considerarse al natural para colmar estas lagunas, pero hay veces que los operadores se resisten a ello, al apreciar una cierta autonomía el determinado subsistema con que operan: el derecho administrativo, en ciertas áreas del derecho comercial, etc. ${ }^{32}$.

c) La regla de la temporalidad: $\mathrm{El}$ artículo $9^{\circ}$ dispone que la ley sólo puede disponer para lo futuro. Ya sabemos que esta norma no obliga al legislador y que nuestra Constitución, en todo caso, impone ciertos límites al legislador para dictar leyes con efecto retroactivo; en el derecho privado el más señalado es la protección que se hace del derecho de propiedad.

La aprobación del Código Civil obligó a promulgar una ley especial que resolviera los problemas de aplicación de leyes en el tiempo, o de derecho inter temporal: Ley sobre Efecto Retroactivo de las Leyes, de 1861, que ayudó a solucionar esos problemas y en general a resolver los problemas de aplicación el tiempo de las nuevas leyes.

Sin perjuicio de la casuística que sigue la ley, como criterio general no es fácil determinar con precisión cuándo estamos frente a una mera expectativa o un derecho adquirido, que sería el divortio aquarium, que acusa la aplicación retroactiva de una ley, cuando tal efecto no es ordenado por ella misma. Por último, sabemos que las mismas leyes suelen traer un derecho transitorio, precisamente para reforzar la regulación y los conflictos que suscita del derecho intertemporal.

d) Los contratos celebrados incorporan las leyes vigentes a su celebración.

Esta norma contenida en el artículo 22 de La ley de Efecto Retroactivo es muy importante, porque viene a fijar el marco ordenar de un contrato: el contrato tiene este efecto abrazador o atractivo de las leyes vigentes al tiempo de su celebración.

32. VERGARA BLANCO, Alejandro: ob. cit., pp. 975-976.

Revista de Ciencias Sociales - Número 66 (2015) - Universidad de Valparáíso - ISSN 0716-7725-Valparaíso, Chile 
Cualquiera modificación legal, como regla, no podría afectar a los contratos en curso, salvo, que se trate de reglas o normas de orden público, que se explica: rigen in actum, La prescripción conectada con la garantía del derecho de propiedad, puede hacer muy difícil intervenir contratos en curso. Pero la verdad es que una interpretación extrema puede llevar a la petrificación del sistema legal, por ello la realidad ha sido más flexible que la teoría, especialmente en derecho laboral, de seguridad social, etc. Por otra parte, la norma sobre derechos reales es mucha más flexible en la misma Ley Sobre Efecto Retroactivo de las Leyes (art. 12), pues, sujeta a la ley antigua a las reglas sobre constitución de los derechos, pero las que tienen que ver con sus goces y cargas y con su extinción los somete a la ley nueva ${ }^{33}$.

\section{Problemas de interpretación y de hermenéutica en general}

La cuestión de la interpretación, es el tema metodológico más importante, pues dice relación con la definición de la manera que el operador debe comprender, explicar y aplicar las normas.

Andrés Bello, que todo lo había pensado y mucho, comprendiendo la gravedad de un sistema abierto de interpretación, que pudiera derivar en una especie de gobierno judicial, y en pleno apogeo de la doctrina de la exégesis en el derecho francé ${ }^{34}$, comprometió al Código con reglas de interpretación de las leyes, que la doctrina corriente entiende que no son meros consejos, sino que aspiran a ser obligatorias, es decir el juez debe necesariamente respetarlas en su proceso de aplicación, formando parte del entramado normativo, a todos los efectos.

33. Sobre estos temas, BARAONA GONZÁLEZ, Jorge: "Irretroactividad de la ley e Intangibilidad contractual. A propósito del fallo del Tribunal Constitucional de la deuda subordinada del sistema bancario". En: Derecho de los Contratos, Universidad de los Andes, Cuadernos de Extensión Jurídica 6, Santiago, Editores H. Corral y G. Acuña, 2002, Págs. 47 y ss.

34. Cfr. GAUDEMET, Eugene: Linterprétation du Code civil en France depuis 1804, Éditions La Mémoire du Droit, Paris, 2002, págs. 43-110.

Facultad de Derecho y Ciencias Sociales - Universidad de Valparaíso - Chile 
El artículo 19 del CC es la regla clave: "Cuando el sentido de la ley es claro, no se desatenderá su tenor literal, a pretexto de consultar su espíritu.

Pero bien se puede, para interpretar una expresión obscura de la ley, recurrir a su intención o espíritu, claramente manifestados en ella misma, o en la historia fidedigna de su establecimiento".

Sabemos también que históricamente, desde Luis Claro Solar, la doctrina nacional y nuestra Corte Suprema estiman que las reglas de interpretación siguen los criterios de Savigny, y ven en las reglas del los artículos 19 a 24 CC sus criterios, cánones o elementos de interpretación: gramatical, histórico, lógico y sistemático, aunque es obvio que el elemento histórico de nuestro Código nada tiene que ver con lo histórico en el sistema de Savigny ${ }^{35}$.

El desafío que nos proponen estas reglas, consiste en determinar si lo que exigen en la ley es claridad de sentido o meramente gramatical.

Históricamente, no puede haber dudas, es Hans-Georg Gadamer quien hizo un aporte fundamental en esta materia, al integrar la hermenéutica, como forma de comprensión, en la construcción general de un sistema hermenéutico ${ }^{36}$. Su idea estaba iluminada por la filosofía de Heidegger, en Ser y Tiempo, para quien el problema del ser sólo podía entenderse desde su realidad histórica, o facticidad: el "Daseim" (o "ser-ahî" o "estar-ahî", según se prefiera ${ }^{37}$ ), para Gadamer, el paso que seguía era iluminar esa manera de comprender y es lo que aborda en su monumental obra ${ }^{38}$.

Lo de Gadamer es una hermenéutica filosófica, por mucho que proponga el método jurídico (y el teológico) como clave para el resto del impulso hermenéutico.

35. Vid. GUZMÁN BRITO, Alejandro: "El Código Civil de Chile y sus primeros intérpretes. En: Revista Chilena de Derecho, Vol 19 N 1, 1992, págs. 81 y ss.

36. Vid. GADAMER, Hans-Georg: Verdad y Método, Décimo Primera Edición, (traducción de Ana Aguad Aparicio y Rafael de Agapito), tomos I y II, 2005.

37. Superando el impulso filosófico de DILTHEY, el conde de York y a su propio maestro Edmund HUSSERL.

38. Vid. Ibíd. cit., pp. 305-377.

Revista de Ciencias Sociales - Número 66 (2015) - Universidad de Valparáíso - ISSN 0716-7725-Valparaíso, Chile 
El problema de fondo es saber si podemos apuntar a un sentido objetivo de interpretación, que aleje al operador del subjetivismo, y al juez de la arbitrariedad ${ }^{39}$, y que conduzca a soluciones unívocas, pasando por la complejidad del proceso, como era la tesis que propugnaba Betti ${ }^{40}$ y que le hizo disputar con Gadamer ${ }^{41}$.

Lo que queramos o no, en un contexto democrático, estos juicios deben ser socializados, y contar con una ambiente general de aprobación. Por ello, no conviene en estas materias el solipsismo científico, o judicial, sino que debe postularse una objetividad consensuada. El sentido de la comprensión necesita necesariamente confirmación social.

Si es claridad de sentido, ¿̇quiere decir que no cabe en nuestro Código aplicar el brocardo clásico: in claris non fit interpretatio? $\mathrm{O}$ por el contrario, debemos seguir el criterio hermenéutico, para afirmar que toda norma debe ser interpretada y sólo así conocer su sentido.

El tándem entre literalidad y espíritu que aparece en el artículo 19 CC, que es clásico, nos desafía: ¿Cuándo y cuánto de literalidad?; ¿cuándo y cuánto de espíritu?

El punto que quiero transmitir es que en una época como la que vivimos, de intensa discusión sobre el sentido de la especulación y de la verdad y que no puede dejar de afectar a la dogmática jurídica,

39. Una crítica a la hermenéutica Gaderiana, con apoyo en los planteamientos de KAUFMANN y ESSER, en GARCÍA AMADO, José Antonio: "Filosofía Hermenéutica y Derecho”. En: http://www.uco.es/dptos/ciencias-juridicas/filosofiaderecho/diego/Nuevo/FILOSOFIA/materiales.

40. Cfr. BETTI, Emilio: La Interpretación jurídica, Prólogo de Guliano Crifó, (compilación y traducción de Alejandro Vergara Blanco), LexisNexis, Santiago 2006, págs. 7-11. Betti también indaga por la hermenéutica en el campo de la interpretación de las leyes, bajo los criterios del conocer los valores éticos o estéticos, pero buscando una objetividad, y diferenciándola de los fenómenos exteriores, porque aquí tenemos una apreciación de tipo intuitivo, desde la sensibilidad ética o estética de cada sujeto, que aprueba o rechaza, bajo reglas que estima son propias de una ley que se descubre.

41. Cfr. PICONTÓ NOVALES, Teresa: "Teoría general de la interpretación y hermenéutica jurídica: Betti y Gadamer”. En Anuario de Filosofía del Derecho, IX, 1992, págs. 223 y ss.

Facultad de Derecho y Ciencias Sociales - Universidad de Valparaíso - Chile 
aunque parezca paradójico, debemos poner un acento fuerte en respetar estos cánones y, por otra parte, en justificar argumentativamente ${ }^{42}$ nuestras interpretaciones, de forma de hacerlas objetivamente criticables. Aunque es cierto que en el derecho hay un amplio campo para la discusión, lo clave es que nos pongamos de acuerdo en las vías para dirimir estos criterios, siempre teniendo presente que, en todo caso, es en la etapa de la adjudicación judicial, donde debemos esperar la solución final ${ }^{43}$.

\section{Distinción en lo fáctico y lo normativo}

Otro aspecto que es importante detectar es la necesidad de separar lo estrictamente normativo, de lo que es puramente fáctico.

Las proposiciones normativas tienen por función regir u ordenar una determinada situación o conducta. Por ello, conviene separar muy bien lo que es lo prescriptivo en la disposición de lo que es fáctico.

En este punto, me parece clave el respecto por la realidad extramental, en este caso, por la materia que se regula, que en otras latitudes permite hablar de la "naturaleza de la cosa". En materia contractual en el artículo 1546 se expresa cuando se refiere a "naturaleza de la obligación", o en el artículo 1563 CC, cuando se remite la "naturaleza del contrato".

La idea del la materia, de la realidad, de hecho puro, con influencia normativa me parece esencial, pues, es un método para conectar norma, realidad, e interés privado.

42. KALÍNOWSKI: "Los raciocinios jurídicos así definidos pueden dividirse, paralelamente a los raciocinios en general, en tres grupos: raciocinios jurídicos de coacción intelectual (raciocinios jurídicos lógicos), raciocinios jurídicos de persuasión (raciocinios jurídicos retóricos) y raciocinios jurídicos de argumentación puramente jurídica, basada sobre presunciones, prescripciones, ficciones, etc., establecidas por ley (raciocinios jurídicos extralógicos”). Citado por VIGO, Rodolfo Luis: "De la interpretación de la ley y la argumentación desde la Constitución: Realidad, Teorías y valor. En: Diakaion, Año 26, Junio, N 1, 20129, pág. 224.

43. De esa manera puede entenderse la provocativa síntesis de la hermenéutica de KAUFMANN O HASSEMER que "aplicar derecho es descubrirlo", en tanto la respuesta para un caso siempre supone algo de creación o ajustamiento particular. (En: VIGO, Rodolfo Luis: Ibíd, págs. 187-227).

Revista de Ciencias Sociales - Número 66 (2015) - Universidad de Valparaíso - ISSN 0716-7725-Valparáís, Chile 
Incluso en lo meramente normativo, podemos distinguir preceptos abiertos, o de apreciación normativa muy amplia o indeterminada, denominados cláusulas generales: la noción de culpa, por ejemplo; de otras más específicas, que asumen un marco más regulado en la calificación: la existencia o no de mora en el deudor, por ejemplo ${ }^{44}$.

Frente a ello, es decir lo estrictamente normativo, encontramos lo fáctico, cuya función es darle el supuesto de operación o aplicación del precepto normativo en la realidad a la que se aplica.

Lo que es fáctico, es materia de prueba, y requiere por lo mismo de verificación.

Los hechos ${ }^{45}$ pueden apreciarse por los sentidos, que es la manera más simple de reconocerlos: lo que alguien dijo o no dijo, a partir de las palabras que expresó, o lo que alguien hizo o no hizo a partir de un comportamiento externo que se describió; lo que se vio u oyó, etc.

Luego hay hechos que se perciben como propios, pero que no son más que representación de situaciones: molestia, alegría, estados de ánimo en general, comportamientos significativos: v. gr. saludos, despedida, contaminación del agua, daño corporal desde una herida. Hay elementos de calificación subjetiva allí, que hay que saber depurar.

Por último, hay hechos que se deducen, pero no se conocen, como la intención en la declaración de voluntad, que sólo se percibe por lo que se expresa, por el lenguaje o el comportamiento.

Hay otros hechos que están asumiendo una valoración social: una cosa estropeada o defectuosa, mal trato, insensibilidad frente a una circunstancia, algo nuevo o viejo, todo ello exige depuración.

Hay hechos que conllevan una valoración jurídica: el pago.

Hay materias que son complejas, porque presentan, al mismo tiempo una dimensión normativa y una fáctica, por ejemplo: la cuestión de la causalidad, en la responsabilidad civil, o la interpretación contractual.

44. Cfr. ENGISH, Karl: La idea de concreción en el derecho y en las ciencias jurídicas actuales, (estudio preliminar y traducción de Juan José Gil Cremanes), Ediciones Universidad de Navarra, Pamplona, 1968, págs. 187 y ss.

45. LARENZ, Karl: ob. cit., págs. 272 y ss.

Facultad de Derecho y Ciencias Sociales - Universidad de Valparaíso - Chile 


\section{Los valores en el derecho privado}

En materia de valores en el derecho, la discusión pareció clausurada para los estrictamente positivistas, cuando admitieron, siguiendo a Kelsen, que el orden legal es puramente formal, y por lo mismo no cabe respecto de él validarlo desde la axiología, en el sentido de afirmar la vigencia o no vigencia de una norma por la vía valorativa; los valores y el derecho pertenecerían a dos órdenes diferentes.

La cuestión ha sido frontalmente discutida por el iusnaturalismo, cuando proclama que el derecho es un orden normativo, que encuentra su justificación, y validez por lo mismo, en la virtud de la justicia. Quien dice justo dice legal, quien dice injusto, predica lo contrario al Derecho. Luego, la sola legalidad no basta si no reúne criterios suficientes de justicia.

Con el tiempo se han generado doctrinas no positivistas, que apuntan a una apertura del Derecho a los principios (Dworkin, ALEXY).

Pero el punto es saber si aparte de la cuestión misma de un determinado principio, que ya abordé, podemos entender incluido algún tipo de valoración.

La cuestión filosófica de lo que es un valor es difícil de determinar, porque apunta a algo difícil de percibir, lo valioso requiere de un patrón de medición y a veces de comparación.

Uno puede percibir que el sistema valora, por ejemplo, cuando habla de la dignidad humana (art. $1^{\circ}$, inciso $1^{\circ}$ Constitución), lo que no significa que no contenga un principio operativo o de aplicación prescriptiva.

Otro valor que puede extraerse de la misma constitución, es la familia, como sociedad valiosa, cuando llama a fortalecerla y protegerla (art. $1^{\circ} \mathrm{CPR}$ ).

Otro bien, valioso, es la vida humana en cuanto la Constitución la protege (art. $\left.19 \mathrm{~N}^{\circ} 1 \mathrm{CPR}\right)$.

Libertad, igualdad, interdicción de la arbitrariedad, libre y leal competencia bajo el orden económico actual, son bienes o valores importantes. Esta última es la vía que los países tienen de asegurar la libertad de precios y lo más importante, que ellos sean los justos. Esto supone un combate directo a toda forma de monopolio, de abuso de

Revista de Ciencias Sociales - Número 66 (2015) - Universidad de Valparáíso - ISSN 0716-7725-Valparaíso, Chile 
posición dominante, cartelización de precios, concentración económica y un largo etc.

Es imposible convenir una adecuada metodología del derecho privado, sin tener presente el marco económico y los valores en que los contratos deben operar, y que en nuestro país se le ha denominado orden público económico ${ }^{46}$. Claro, porque de otra manera tenemos un derecho ciego e insensible.

Desde aquí uno podría extraer un criterio de que hay principios que son meramente operativos, que no conllevan en sí un valor (la regla de la especialidad, por ejemplo) y otros que sí connotan una valoración (el interés superior del niño, en materia de infancia, por ejemplo).

Desde esta constatación podemos formular criterios valorativos, a la hora de interpretar las normas para darle mayor o menor incidencia a interpretaciones que conlleven una mayor protección de bienes legalmente valiosos: la dignidad de la persona; la protección de la familia; el superior interés del niño; la protección del trabajador en materia laboral, la necesidad de darle protección a quién está de buena fe, la no discriminación arbitraria, etc., la libre competencia, etc.

En el orden más práctico, hay valoraciones que la misma ley exige al juez que haga, como buenas costumbres, orden público, justa causa, buena o mala fe, malicia, razonable, prudente o imprudente, en fin, todos son juicios de apreciación fáctico-normativo, que conllevan una valoración moral.

\section{Lo conceptual, lo tópico y lo descriptivo}

El peligro que se le atribuye a nuestro modelo metodológico, es que tiende a ser excesivamente abstracto y con ello sumamente genérico y conceptual, en donde el afán sistemático y el proceso lógico-deductivo amenazan, a veces, para encontrar la solución adecuada, justa, al problema. Con ello el derecho pierde la ductibilidad necesaria para

46. FERMANDOIS V., Arturo: Derecho Constitucional Económico, Tomo II, Ediciones Universidad Católica de Chile, Santiago, 2010, pág. 29.

Facultad de Derecho y Ciencias Sociales - Universidad de Valparaíso - Chile 
reconocer y adaptarse a la realidad, frente a un determinado problema, o conflicto de intereses ${ }^{47}$.

En este sentido, algunas metodologías, huyendo de la sistematicidad abstracta o formal, redescubrieron la tópica, como criterio de aproximación problemático ${ }^{48}$. Aunque el método no es nuevo, pues, hunde sus raíces en la cultura griega y luego romana, y fue practicado por los denominados posglosadores, es Viehweg quien en la mitad de los años 50 del siglo pasado, lo propuso como modelo para superación del sistema cartesiano en el derecho. Aunque ha sido criticado, por ingenuo e impreciso, lo rescato como empeño importante, para generar en el operador una visión menos formal, especialmente en el juez y en el abogado, y para advertirle al jurista dogmático que las soluciones a los problemas que debe resolver no siempre pueden derivarse en pura lógica abstracta desde las normas, sino que requieren una ajustes dialécticos y por lo mismo argumentativos. Los topoi, o formas de pensamiento dadas por lugares comunes (derivadas del sentido común), ayudan a enriquecer una forma de pensar el derecho, que se abra a la realidad ${ }^{49}$.

Otra manera de huir de lo abstracto, es recurrir a criterios sociológicos, apreciando que muchas veces las normas con que nos encontramos son descripciones de la realidad, que no conviene abstraer en exceso, para evitar meras subsunciones lógicas o conceptuales, y emplear, en cambio, comparaciones tipológicas, o incluso valorativas. Figura como la "prestación" o la "mora", más que conceptos, son descripciones tipológicas de la realidad ${ }^{50}$, pues se refieren aspectos a

47. Cfr. EINGISH, Karl: op. cit.

48. VIEHWEG, Theodor: Tópica y Jurisprudencia, (Traducción de Luis DiezPicazo), Taurus, 1986.

49. Cfr. SANZ BAYÓN, Pablo: "Sobre la tópica jurídica en Viehweg”. En: Revista Telemática de Filosofia del Derecho, No 16, 2013, págs. 83-108.

50. Tomo el concepto de DI MAJO, Adolfo: Delle Obbligazioni en generale. En Commentario al Codice civile, Scialoja-Branca, Zanichelli-Foro Italiano, Bologna-Roma, 1988, Pág. 89; y en general la realidad en función normativa ASCARELLI, Tulio: "Norma guiridica e realtà sociale”. En: Problemi Guidirici, t. I, Giuffrè, Milano, 1959, págs. 69-111. 
reproducciones fáctico-normativas interconectadas, tomadas de la propia realidad en que opera el Derecho.

\section{El interés}

Como ya hice notar, la clave metodológica en el derecho privado, dice relación con la idea del interés ${ }^{51}$ privado.

Quiero poner el acento en el derecho contractual, que en su base apunta a que las partes contratantes deciden celebrar un contrato atendiendo a intereses personales, que desean alcanzar o proteger.

Todo contrato tiene como base un empeño privado orientado a un fin, una operación económica, cuya realización es querida por ambas pues, de alcanzarse derivan beneficios económicos ${ }^{52}$. Quien dice contrato expresa una operación económica ${ }^{53}$. Me parece que esta es una cuestión crucial, pues, el derecho debe encontrar vías para detectar y hacer operativos esos intereses; los principios de la buena fe y de la colaboración contractual, apuntan precisamente en esta línea. Pero no solo ellos, también categorías como al objeto contractual, la causa contractual, la

51. La cuestión del interés ha sido muy importante desde que lo planteara JHERING, Rudolph v.: El fin del Derecho, Comares, Granada, 2000; luego GÉNY, Francisco, Método de Interpretación y Fuentes en el Derecho Privado Positivo, Comares, Granada, 2000; más adelante HECK, Philipp: El problema de la creación del derecho, Colofón, (versión castellana de Manuel Entenza), México DF, 1994; una presentación de la jurisprudencia de intereses, como empeño metódico. En: LARENZ, Karl, op. cit, págs. 141-151.

52. Sobre el tema BARAONA GONZÁLEZ, Jorge: El Retraso en el Cumplimiento de las Obligaciones, Dykinson, Madrid, 1998, págs. 181 y ss., y la doctrina allí citada; en el derecho francés, bastante reacio a este tipo de reflexiones, existen tesis en esta misma dirección, PIMONT, Sébastien: L'economie du contract, Presses Universitaires D'Aix-Marseille-PUAM, Aix-En-Provence, 2004; y DO, Van Dai: Le $r \mathrm{O} l$ de l'interêt prive dans le contrat en Droit Francais, Presses Universitaires D'AixMarseille, 2004, entre otras.

53. Vid. GAZMURI LARRAÍN, Daniela: El contrato como operación económica, tesis para optar al Grado de Licenciada en Derecho, U. de los Andes, Santiago de Chile, 2009, dirigida por el autor de este trabajo que es importante por la bibliografía que allí se refiere y las conclusiones a que fundadamente llega.

Facultad de Derecho y Ciencias Sociales - Universidad de Valparaíso - Chile 
diligencia debida en cuanto promotora del cumplimiento ${ }^{54}$, permiten poner en el centro esos intereses, y coordinar la actuación de las partes para su adecuada satisfacción.

El telón de fondo no puede ser otro que una adecuada explicación de las reglas sobre interpretación contractual.

Lo clave está en determinar qué han querido las partes, como fruto de su acuerdo o consentimiento, es decir el fin del contracto. Esto impone el desafío de no mirar hacia las obligaciones generadas por el contrato, como a elementos estáticos y meramente normativos, sino más bien como descripciones de comportamientos funcionalizados, que apuntan a la satisfacción de los intereses de ambas partes, los que han quedado suficientemente recogidos en la estructura contractual.

Un desarrollo muy importante en esta línea se parecía en el nuevo derecho contractual que últimamente la profesora Pamela PRADO ha puesto de relieve $e^{55}$, al estudiar el deber del acreedor al cumplimiento de la obligación, poniendo de relieve el interés del deudor en ejecutarla, a fin de liberarse de responsabilidad.

\section{La influencia de los Tratados Internacionales, la Constitución y del derecho del consumidor en el derecho privado}

\subsection{Los tratados internacionales sobre derechos humanos y en general las garantías constitucionales y el derecho privado}

Desde hace tiempo se viene advirtiendo la creciente influencia de las garantías constitucionales en el derecho privado, por la vía de irradiar las relaciones entre particulares, la doctrina de los Drittwirkung, ya sea en forma indirecta, iluminando la interpretación que de las normas privadas se puede hacer desde la Constitución, como en la postura más extrema, llamando a aplicar directamente la Constitución

54. Sobre esta noción, con un impresionante estudio histórico y de fuentes, BADOSA COLL, Ferrán: La diligencia y la culpa del deudor en la obligación civil, Publicaciones del Real Colegio de España, Bolonia, 1987.

55. PRADO LÓPEZ, Pamela: La colaboración del acreedor en los contratos civiles, Thomson Reuters, Santiago, 2015.

Revista de Ciencias Sociales - Número 66 (2015) - Universidad de Valparáíso - ISSN 0716-7725-Valparaíso, Chile 
incluso en las relaciones de derecho privado, de forma de asegurar que las garantías y derechos que la Constitución reconoce y asegura serán respetadas incluso en esta esfera ${ }^{56}$.

Desde la óptica del derecho internacional de los derechos humanos, se puede advertir una creciente influencia en el derecho privado, pues, se aprecia una revalorización de aspectos que antes no parecía posible hacer operativos, sin la mediación de la propia ley. Pero el desarrollo del derecho ha hecho que los jueces se sientan llamados a darle operatividad a las normas sobre derechos humanos, contenidas en tratados internacionales, y con ello, ejercer lo que se denomina el control de convencionalidad de las leyes, de cara a una interpretación funcional a la promoción y protección de tales derechos.

Cuestiones como el interés superior del niño, la dignidad de la persona, el derecho a no ser discriminado, el derecho a la educación y a la salud, la libertad de conciencia, el debido proceso, por poner algunos temas, hoy ya no requieren de mayor concreción legislativa.

Adicionalmente, es posible indicar que la creciente importancia de la administración en la regulación contractual privada y que hace 20 años parecía en retirada, se explica por el importante desarrollo que ha tenido en el mundo entero, especialmente en países económicamente más poderosos, los temas relativos al medioambiente y el equilibrio socio-económico en general, generado por crisis financieras tanto en los Estados Unidos de América como en la Unión Europea y por el desarrollo que de lo que hoy se afirma como los derechos de solidaridad o derechos de los pueblos: autodeterminación, desarrollo, medioambiente sano, paz.

Las convenciones y tratados sobre derechos humanos y las constituciones, emergen así como elementos normativos, que superan la mera función de ser "diques de protección" frente al poder, por la vía de limitar la autoridad y evitar que se abuse de los derechos humanos ${ }^{57}$, para constituirse en un marco protector que irradia todo el sistema.

56. Un estudio muy completo sobre el tema, en VENEGAS GRAU, María: Derechos fundamentales y Derecho privado, Marcial Pons, Madrid, 2004.

57. Por la importancia del tema, por quien lo expone y el contenido de lo que expresa, Vid. discurso del Sr. Presidente de la Ex. Corte Suprema Sergio

Facultad de Derecho y Ciencias Sociales - Universidad de Valparaíso - Chile 
Un constitucionalismo con fuerte contenido social ${ }^{58}$ ha emergido de las mismas cartas fundamentales y, por sobre ellas, de los tratados de derechos humanos, civiles, políticos, sociales y culturales, como una expresión de valores y principios, que cada Estado debe reconocer, proteger y promover, y no únicamente como expresión estática frente a una realidad que deba evitarse, sino como expresión dinámica de la misma acción del Estado, que se erige en fuente de su propia legitimación ${ }^{59}$.

Se trata de un sistema también jurisdiccional ${ }^{60}$, porque por medio de las Cortes de Derechos Humanos, Tribunal de Roma, Corte Europea, Corte Interamericana, Tribunales Constitucionales, no sólo se va buscando asegurar la vigencia de estos criterios, sino además nutriendo de una frondosa doctrina que va permeando los sistemas nacionales ${ }^{61}$.

Muñoz, en el Primer Foro Interamericano de Justicia Ambiental, 10 de octubre de 2014, http://www.pjud.cl/documents/10179/1478806/Discurso+1\%C2\% BA\%20 Foro+Interamericano+de+Justicia +Ambiental+ +\%2810+de+octubre+de+2014\%29.pdf/ bc6ab22f-1310-4a48-9c21-d4f2ef00d263? version $=1.0$

58. Una visión crítica de esta evolución nace del estudio de BRAVO LIRA, Bernardino: Constitución y Reconstitución, "Historia del Estado en Iberoamérica 1511-2009”, Editorial Legal Publishing Chile, Santiago, 2010, pág. 144.

59. Sobre dogmática iusfundamental puede verse en Chile, ALDUNATE LIZANA, Eduardo: Derechos Fundamentales, Editorial Legal Publishing Chile, 2008, págs. 104-105, quien expone una mirada crítica al proceso que conduce a darle operatividad a los derechos fundamentales en el sistema legislativo, por el riesgo de vaciarlos de contenido.

60. Cfr. NOGUEIRA ALCALÁ, Humberto: "El valor jurídico asignado por la jurisprudencia del Tribunal Constitucional al derecho convencional internacional de los derechos humanos y su fuerza normativa en el período 20062013”. En: Revista Chilena de Derecho, Facultad de Derecho Pontificia Universidad Católica de Chile, Vol. 41 - N² 2, 2014, págs. 409-435.

61. En el considerando que sigue se nota esta influencia, para armonizar el derecho contractual con el derecho a la educación: "Séptimo: Que, según se advierte del basamento anterior, se faculta a la Universidad respectiva a retener por concepto de costos de administración hasta el $1 \%$ del arancel anual de la respectiva carrera, con lo que, en el caso de autos, el retracto presentado con un día de desfase en relación al plazo fatal indicado

Revista de Ciencias Sociales - Número 66 (2015) - Universidad de Valparáiso - ISSN 0716-7725-Valparáís, Chile 
Jorge Baraona González

Esto es importante, porque tal concepción conlleva una carga ideológica que necesariamente ha de impactar en la contratación privada $^{62}$ y que en Chile comenzamos a advertir con un sentido más intenso a nivel legislativo, y también por acción de la propia autoridad

que cobra un $20 \%$ del arancel anual resulta arbitrario. En efecto, se está en la hipótesis que al iniciar la Universidad el proceso definitivo de planificación de actividades la recurrente dio cuenta de su decisión de no perseverar en sus estudios, por lo cual no se ha producido un daño superior al normal a cualquier retracto temporario. Es esta circunstancia, unida a la voluntad de la Universidad de no perseverar en el contrato educacional, la cual denotó un exceso en las exigencias pecuniarias lo que afecta la garantía prevista en el artículo 19 $N^{\circ} 24$ de la Carta Política, por cuanto hace soportar a la recurrente un costo mayor al que razonablemente ha debido soportar la Universidad, el que se entiende proporcional a un porcentaje igual al fijado por el legislador por 10 días, esto es al $1 \%$ del arancel anual, conforme a lo cual la alumna deberá pagar ambas cantidades, las que suman un 2\% del arancel anual, más la matrícula respectiva” (CS, Protección, Rol N² 24920-2014). Otro caso, es un problema presentado por un paciente que intentaba hacer uso de CAEC (Cobertura Adicional de Enfermedades Catastróficas), se puede apreciar un criterio similar para resolver un conflicto de un derecho legal, en el marco de un contrato de salud previsional: "Tercero: Que la finalidad que se desprende de la lectura de la Circular $N^{\circ} 7$, de 01 de julio de 2005, no ha sido otra que la de aumentar la cobertura que se otorga al afiliado y sus beneficiarios, siendo deber de la institución recurrida poner a disposición de sus abonados un sistema conformado por una Red Cerrada de Atención y modalidad de atención médica cerrada, cuya finalidad precisamente es la de prestar atención de salud a dichas personas ante la eventualidad de presentar alguna de las enfermedades catastróficas cubiertas por el beneficio adicional.

Pues bien, en el caso de autos ello no ha funcionado del modo previsto por una causa que no es imputable al paciente, dada la imposibilidad de su traslado, de modo que lo que correspondía era que la Isapre diera a la estipulación contractual una interpretación que atendiera la finalidad de la misma y que no se amparase en su facultad discrecional de designar al prestador. No cabe, en consecuencia, confundir la discrecionalidad, esto es, el uso motivado de las facultades de arbitrio, con la arbitrariedad, que consiste en la no motivación de las facultades discrecionales.

En este caso, la Isapre no ha dado ninguna explicación atendible para justificar su negativa a otorgar la cobertura CAEC, aun ante la imposibilidad de traslado del paciente". (CS, Protección, Rol N²3036-2014).

62. Cfr. ALCALDE RODRÍGUEZ, Enrique: "Relación entre valores y principios generales de Derecho en la interpretación constitucional de los derechos fundamentales en Chile”. En: Revista Chilena de Derecho, Facultad de Derecho Pontificia Universidad Católica de Chile, 2008, Vol. 35 - Nº 3, 2008, págs. 463-484.

Facultad de Derecho y Ciencias Sociales - Universidad de Valparaíso - Chile 
e incluso en un nivel más decantado por su particularización, como es el de la actuación judicial ${ }^{63}$.

Desde el ámbito estrictamente económico, las cuestiones de libre competencia $^{64}$ y de la lealtad en la competencia ${ }^{65}$, también tienen una esencial incidencia en la libertad y contenido de la contratación, según puede desprenderse de la legislación particular que existe sobre esta materia.

En consecuencia, estamos frente a un nuevo desafío que dice relación con aspectos epistemológicos, de fuentes por lo mismo, donde pierden centralidad los Códigos, en el contexto de una dispersión normativa que debe ser reordenada ${ }^{66}$; hay una valoración distinta de

63. Sobre el tema, y por la importancia de autor por ser un destacadísimo profesor de derecho civil argentino y de gran influencia continental, y además es el actual Presidente de la Corte Suprema de la Nación Argentina, LORENZETTI, Ricardo Luis: Razonamiento Judicial Fundamentos de Derecho Privado, IDPL- Grijley, Lima, 2006, quien aboga por un reordenamiento a base de nuevos criterios de derecho privado, que decanten el razonamiento judicial, articulado en un sistema en el que confluyen normas, principios y paradigmas de decisión, que permita superar la abstracta formulación de los Códigos, destrozada por lo que denomina el "big bang" de fuentes alternativas. Con un sentido crítico respecto de corrientes metodológicas como el valorismo o el nuevo derecho y del activismo judicial en general, instando por hermenéutica basada en la semántica, el no menos conocido ex Magistrado de la Corte Suprema de su país, TAMAYO JARAMILLO, Javier: Manual de Hermenéutica Jurídica, Análisis constitucional, legal y jurisprudencial, Extracto adaptado y adicionado de la obra "La decisión judicial", Diké, Medellín, 2013.

64. Por todos VALDÉS PRIETO, Domingo: Libre Competencia y Monopolio, Editorial Jurídica de Chile, Santiago, 2009.

65. Por todos CONTRERAS BLANCO, Oscar: La competencia desleal y el deber de corrección en la Ley chilena, Ediciones PUC, Santiago, 2012.

66. LORENZETTI, Ricardo Luis, op. cit., págs. 46 y 47: "Lo correcto es diferenciar a través del posicionamiento jerárquico de normas. Esa era la función del Código, como una ley superior o 'sacra'. La proliferación de leyes es una 'desacralización', ya que, al abundar, las normas adquieren un carácter instrumental que las devalúa. Hay una dinámica de la creación continua de leyes e instituciones y un subsiguiente deslizamiento jerárquico. En ese contexto vuelve a cobrar realce la hermenéutica, en tanto reconstrucción del sistema, identificando las normas fundantes, las derivadas y su vinculación interna”.

Revista de Ciencias Sociales - Número 66 (2015) - Universidad de Valparáíso - ISSN 0716-7725-Valparaíso, Chile 
aspectos que antes no parecían sensibles al Derecho y que exigen una reflexión profunda sobre el sentido de la justicia, en un contexto socioeconómico complejo y diverso. Se advierte una evidente vuelta a la confianza en el Derecho como vehículo de cambio social, que parecía en retirada, lo que desafía a los estudios de hermenéutica e interpretación jurídicas ${ }^{67}$.

Así, en la sentencia de la ley de Isapres, el Tribunal Constitucional expresó que "cabe concluir que las normas que regulan el contrato de salud, sean legales o administrativas, deben ser interpretadas y aplicadas en términos de maximizar el disfrute real y pleno de los derechos que son consustanciales a la dignidad humana, entre ellos, el derecho social relativo a la protección de la salud, en los términos asegurados a todas las personas en el artículo $19, \mathrm{~N}^{\circ}$ 9, de la Constitución, precepto que se erige en base constitucional y de orden público que informa, con calidad de ineludible e inafectable, toda convención de esa índole" ${ }^{68}$.

Una afirmación de la misma índole ya había sido efectuada por el Tribunal Constitucional en el denominado caso de la "píldora del día después", en donde sostuvo "[e]n esta perspectiva debe también agregarse que, para el constitucionalismo contemporáneo, los derechos fundamentales — que se aseguran a todas las personas - poseen una doble naturaleza que justifica su rol central en las Cartas Fundamentales y en los instrumentos internacionales de derechos humanos. Por un lado, constituyen facultades que se reconocen a su titular, dando lugar a su dimensión 'subjetiva', mientras que, por otro, dan unidad y sentido a todo el ordenamiento jurídico, lo que se conoce como su dimensión 'objetiva'. De allí que todo conflicto constitucional que, como el de la especie, tienda a constatar la eventual vulneración de derechos fundamentales tiene una especial significación que no puede dejar indiferente a ningún operador del derecho" ${ }^{69}$.

67. A este respecto TAMAYO, Javier: op. cit., págs. 28 y 29.

68. Tribunal Constitucional de Chile: Requerimiento de inaplicabilidad deducido por Silvia Peña Wasaff respecto del artículo 38 ter de la Ley $N^{\circ} 18.933$, conocida como Ley de Isapres, en recurso de protección contra Isapre ING Salud S.A., Rol de Ingreso $N^{\circ}$ 4972-2007, de la Corte de Apelaciones de Santiago. Rol 976-2008. Sentencia de fecha 26 de junio de 2008 . Considerando $39^{\circ}$, p. 36.

69. Todo en AGUILAR CAVALLO, Gonzalo: "Principio de solidaridad y derecho privado: comentario a una sentencia del Tribunal Constitucional". En: Ius et

Facultad de Derecho y Ciencias Sociales - Universidad de Valparaíso - Chile 
Nuestro sistema Constitucional, por vía del artículo $6^{\circ}$ o el mismo artículo 20, que consagra el recurso de protección, podría dar margen a la doctrina más entusiasta.

También existen normas legales que ya incorporan esta doctrina en las relaciones privadas, como es el caso de los arts. 485 y ss. del Código del Trabajo.

Cuando no hay norma legal, la cuestión no es de fácil solución, desde un punto de vista metodológico, porque que sería poco razonable pensar que, sin mediación de la ley, la Constitución no pueda impactar las relaciones del derecho privado. Pero obvio, tampoco es fácil admitir su mediación hasta el punto de romper la estructura operativa que el derecho privado ofrece y que hemos perfilado.

Pienso que el tema tiene distintos niveles de aplicación.

No hay duda que aquellos valores de profundo significado constitucional, como la libertad, dignidad, igualdad, autonomía, etc., que ya hemos revisado, y por ello sí impactan las relaciones privadas, porque el derecho privado encuentra su límite en la ley, las buenas costumbres el orden público.

Tampoco debiera despertar mayores dificultades la iluminación de las normas de derecho privado, "conforme con la Constitución”.

Cuestión distinta es que la indeterminación de tales términos, pueda dar margen a una actuación judicial arbitraria o discrecional, que melle otros valores del derecho, aparte de la justicia, como es la interdicción de la arbitrariedad y la seguridad jurídica.

Donde el punto es más complejo, es en el nivel de la aplicación directa de la Constitución, para modificar un contrato, o dejar de aplicar alguna ley.

Desde el punto de vista operativo, pienso, siguiendo al profesor Rödl, que el derecho privado tiene una estructura que ha irradiado la Constitución, por lo mismo, no puede decirse que por el hecho de que

Praxis, V. 14, N² 2, 2008, págs. 593-610. Tribunal Constitucional de Chile: Requerimiento de inconstitucionalidad deducido en contra de algunas disposiciones de las "Normas Nacionales sobre Regulación de la Fertilidad", aprobadas por el Decreto Supremo $N^{o} 48$, de 2007, del Ministerio de Salud. Rol 740-2008. Sentencia de fecha 18 de abril de 2008. Considerando $47^{\circ}$.

Revista de Ciencias Sociales - Número 66 (2015) - Universidad de Valparáíso - ISSN 0716-7725-Valparaíso, Chile 
algún criterio que emane de la Constitución, estemos necesariamente incorporando en la relación privada elementos que le son ajenos y que de alguna manera la desnaturalizan ${ }^{70}$.

No puede haber duda, si revisan algunas garantías, que ellas están influidas por la propia ley. Así la noción de familia y persona son incomprensibles sin la luz que ofrece el Código Civil; tampoco la garantía del derecho de propiedad puede comprenderse a cabalidad sin tener presente la regulación que del dominio y de más derechos reales hace el Código Civil; la cuestión de la responsabilidad misma, no parece estar en el Código Fundamental suficientemente desarrollada, y por ello, imprescindible resulta recurrir a la especificación que de ella se hace en la ley. Respecto de la libertad de desarrollar cualquier actividad económica, tal vez puede ser más difícil encontrar su correlato en el sistema del Código Civil, aunque personalmente estimo que esa garantía no puede entenderse sino a la luz de las actuaciones que los particulares pueden desarrollar en el tráfico por la vía contractual, que no es otra cosa que la libertad para desarrollar operaciones económicas ${ }^{71}$.

Todo lo que encaje en la naturaleza propia de la relación privada, estimo, no constituye una verdadera intervención desde la Constitución, sino una privatización de lo constitucional; en cambio, aquellas aplicaciones desnaturalizantes, creo, deben ser mediadas por una ley, desde el momento que sólo por ley las garantías pueden ser reguladas.

Ahora cuando un operador pudiera detectar derechos en conflicto, me parece que lo central está en un ejercicio de ponderación de los mismos, a fin de detectar si hay puntos de armonización, bajos criterios y juicios de racionabilidad y proporcionalidad. No me parece razonable aplicar criterios abstractos, dándole preeminencia a algunos

70. RÖDL, Florian: "Fundamental Rights, Private Law, and Societal Constitution: On the Logic of the So-Called Horizontal Effect". En: Indiana Journal of Global Legal Studies, Vol 20, Issue No 2, 8, 2013, págs. 1015-1034.

71. De una manera general de la influencia de la ley para la interpretación de la Constitución, SILVA IRARRÁZAVAL, Luis Alejandro: "La dimensión legal de la interpretación constitucional". En: Revista Chilena de Derecho, Vol 41, No 2, 2014, pág. 460.

Facultad de Derecho y Ciencias Sociales - Universidad de Valparaíso - Chile 
derechos respecto de otros, pues, ello supone darle una jerarquización a los derechos fundamentales que no siempre es justa.

Con todo, y aunque creo que existen derechos que son superiores, como la vida y la dignidad de toda persona, así como la igualdad y la libertad de todos, la mayoría de los derechos exigen una verdadero juicio de ponderación, que insisto, logre una coordinación entre ellos, por ello la mediación de la ley parece esencial.

\subsection{El impacto de las normas sobre protección del consumidor en el derecho privado chileno}

El derecho del consumidor ha tenido en el sistema del derecho occidental una innegable influencia. Como sabemos la Ley 19.496, que llegó más bien tarde a Chile, y que se ha ido perfeccionando con el tiempo, paulatinamente ha adquirido más importancia. No puede existir duda de que el caso Cencosud ${ }^{72}$ marcó un hito, en cuanto zanjó definitivamente algunas cuestiones de interpretación de la ley que estaban pendientes, y al mismo tiempo comprometió a la Corte Suprema en la lucha en contra de las cláusulas abusivas, particularmente de las que se imponen en el mercado de créditos de consumo, que tienen el mayor impacto, por el alto endeudamiento que muestran las familia en Chile $^{73}$.

Por otra parte, la Ley 19.496 se expandió al sistema de las PYMES (vid. Estatuto de la Pymes Ley 20.416 de 13/02/2010) ${ }^{74}$, es decir tiene,

72. CS, casación civil, Rol 12.355-11. Un comentario al fallo puede verse en PINOCHET OLAVE, Ruperto: "Modificación unilateral del contrato y pacto de autocontratación: dos especies de cláusulas abusivas a la luz del derecho del consumo chileno, comentario a la sentencia de la Exma. Corte Suprema de 24 de abril de 2013 recaída en el "caso Sernac con Cencosud". En: Revista Ius et Praxis Vol. 19, No 01 2013, págs. 365-378.

73. http://www.bcentral.cl/eng/studies/economia-chilena/2014/apr/recv17n1abr 2014-pp88-102.pdf

74. Artículo Noveno “2) Normas Aplicables. Serán aplicables a los actos y contratos celebrados entre micro o pequeñas empresas y sus proveedores las normas establecidas en favor de los consumidores por la ley $\mathbf{N}^{\circ} 19.496$ ley en los párrafos $1^{\circ}$,

Revista de Ciencias Sociales - Número 66 (2015) - Universidad de Valparáíso - ISSN 0716-7725-Valparáiso, Chile 
una vocación regulatoria para relaciones entre las micro y pequeñas empresas (se excluyen las medianas) con sus proveedores (a elección de la pequeña y micro empresa), lo que permite afirmar que no está regulando estrictamente relaciones entre proveedores y consumidores, si consideramos que las PYME son verdaderas empresas, es decir insumidores de productos que adquieren para incorporarlos a sus procesos productivos o de servicios ${ }^{75}$.

Lo anterior tienen un gran impacto, porque si se considera que una pequeña empresa puede calificar como tal si no supera en su facturación anual las UF 25.000 (por sobre los $\$ 6.000 .000$ ), quiere decir que la gran mayoría del tráfico, al menos en términos de los actores, puede llegar a sujetarse a las normas de la Ley 19.496, y eventualmente sus controversias dirimirse ante los Juzgados de Policía local.

Si se revisa la Ley 19.496, se advierte que su regulación, de escasa técnica legislativa, apunta a asegurar ciertos derechos para los consumidores, pero bajo la idea que existe una ley detrás que regula integralmente la relación. Es una estructura de regulación asimétrica, difícil de encajar por lo demás en el derecho común, por esfuerzos que se hagan para ello. No es una ley regulatoria, sino sancionatoria, centrada más en la sanción que en la disposición sustantiva.

Lo anterior puede traer dificultades de aplicación a la hora de ensamblar ambos sistemas, por ejemplo, para hacer operativa la resolución contractual, la nulidad de los contratos, la responsabilidad civil, etc. En estas materias, no resulta fácil saber cuándo y cómo se integran a sus normas las disposiciones del derecho común, civil o

$3^{\circ}, 4^{\circ}$ y $5^{\circ}$ del Título II, y en los párrafos $1^{\circ}, 2^{\circ}, 3^{\circ}$ y $4^{\circ}$ del Título III o, a opción de las primeras, las demás disposiciones aplicables entre partes. En ningún caso serán aplicables las normas relativas al rol del Servicio Nacional del Consumidor. La aplicación de las disposiciones señaladas precedentemente será irrenunciable anticipadamente por parte de las micro y pequeñas empresas.

Para todos los efectos legales, las normas relativas a los medios de prueba contenidas en el Código de Comercio serán también aplicables a los litigios judiciales referidos en el párrafo anterior.

75. La limitación a la prueba de testigos, tradicional en el Código Civil, desaparece Comercio.

en estas relaciones, de acuerdo con lo que dispone el artículo del Código de

Facultad de Derecho y Ciencias Sociales - Universidad de Valparaíso - Chile 
comercial, y por ello las cuestiones metodológicas se hacen muy importantes ${ }^{76}$.

Por último, la materia que mayor influencia tendrá en el derecho común, dice relación con la que regula las cláusulas abusivas, en donde se contiene material normativo que indirectamente va a influir en el derecho común. La libertad de pactos, bajo el prisma del principio de la autonomía de la voluntad, está sufriendo una revisión, para ajustar el proceso de negociación y operación contractual, de forma de hacerlo más justo, evitando abusos derivados de asimetrías de poder.

En el sistema anglosajón la doctrina de la inconscionability, que hunde sus raíces en la equitiy law ${ }^{77}$, fue reverdecida desde la aprobación del UCC, en la década de los años 60 del siglo pasado; de hecho también se incluyó en el Restatement Second, en $1981^{78}$, para el derecho contractual. A su turno, la Unión Europea ha estado revisando reglas sobre cláusulas abusivas que claramente aspiran a regular relaciones entre comerciantes o parte sofisticadas. Esto tiene importancia, porque obliga al operador a desentrañar la estructura básica de las instituciones, de forma tal que no sean desnaturalizadas en los pactos y contratos.

El viejo concepto de "orden público" y la huidiza noción de "buenas costumbres" vuelven por sus fueros, para delimitar la estructura y operación de cada institución.

\section{Conclusiones}

Una mirada panorámica a la metodología del derecho privado, permite afirmar que ha quedado atrás la escuela exegética francesa que

76. Cfr. BARAONA GONZÁLEZ, Jorge: "La regulación contenida en la Ley 19.496 sobre protección de los consumidores y las reglas del Código Civil y Comercial sobre contratos: un estudio comparativo". En: Revista Chilena de Derecho, Vol 41, No 2, 2014, págs. 381 y ss.

77. Sobre el tema WADDAMS, Stephen: "Protection ok weaker parties in English Law”. En: Unconscionability in European Private Financial Transactions Protecting the Vulnerable, (Edited by James Devenny and Lorna Fox O'Mahony), Cambridge University Pres, 2010 (Kindle Edition), New York, pp. 26 y ss.

78. ttps://www.law.cornell.edu/ucc/2/2-302.

Revista de Ciencias Sociales - Número 66 (2015) - Universidad de Valparáíso - ISSN 0716-7725-Valparaíso, Chile 
se contentaba con una mirada rígida sobre la norma escrita y, en afán binario, llevaba a elucidar si ella era clara u obscura, para aplicarla o interpretarla lo más cerca posible de su estructura semántica.

Hoy debemos enfrentarnos a un sistema abierto de fuentes, en donde la relación jurídica de derecho privado debe orientarse funcionalmente a la satisfacción de los intereses de las partes, bajo el marco que ofrece el sistema de derechos fundamentales, en un contexto de integración transfronteriza.

Lo que puede o no puede hacerse, y lo que es jurídicamente prescriptivo, deriva de una aproximación operativa de la realidad concreta, en oposición a un razonamiento excesivamente abstracto.

La seguridad jurídica no emerge sólo de la idea de seguir irrestrictamente una norma o una cláusula, sino de respetar la verdadera protección de los fines y bienes (intereses) que las partes quisieron alcanzar, y que se afianza con una sólida argumentación, llena de sentido.

Enfrentados a conflictos entre derechos fundamentales, es evidente que la cuestión impone un desafío de ponderación de cara a una coordinación de tales derechos, sin desentenderse, dentro de lo posible, del supuesto básico del derecho privado: la justicia que han querido las partes, y que ha quedado recogida en el contrato, o el ejercicio del derecho por el cual ha optado.

Por último, considerando la amplitud de la esfera normativa del derecho del consumidor en Chile, impone un nuevo desafío al operador, por cuanto exigen un adecuado ensamblaje con las reglas del derecho privado de carácter tradicional.

\section{Bibliografía}

ALCALDE RODRÍGUEZ, Enrique: Los Principios Generales del Derecho, Ediciones PUC, Santiago, 2003.

ALCALDE RODRÍGUEZ, Enrique: "Relación entre valores y principios generales de Derecho en la interpretación constitucional de los derechos fundamentales en Chile". En: Revista Chilena de Derecho, Facultad de Derecho Pontificia Universidad Católica de Chile, 2008, Vol. 35 - N 3, 2008, págs. 463-484.

Facultad de Derecho y Ciencias Sociales - Universidad de Valparaíso - Chile 
Metodología del derecho privado a la luz de las convenciones, tratados...

ALDUNATE LIZANA, Eduardo: Derechos Fundamentales, Editorial Legal Publishing Chile, 2008.

ALEXY, Robert: El concepto y la validez Del Derecho, (traducción J. Seña de la edición alemana de 1992), segunda edición, Barcelona, 2004.

AGUILAR CAVALLO, Gonzalo: "Principio de solidaridad y derecho privado: comentario a una sentencia del Tribunal Constitucional”. En: Ius et Praxis, V.14, N² 2, 2008, Págs. 593-610.

ASCARELLI, Tulio: "Norma guiridica e realtà sociale". En: Problemi Guidirici, t. I, Giuffrè, Milano, 1959.

BARAONA GONZÁLEZ, Jorge: El Retraso en el Cumplimiento de las Obligaciones, Dykinson, Madrid, 1998.

BARAONA GONZÁLEZ, Jorge: "Irretroactividad de la ley e Intangibilidad contractual. A propósito del fallo del Tribunal Constitucional de la deuda subordinada del sistema bancario". En: Derecho de los Contratos, Universidad de los Andes, Cuadernos de Extensión Jurídica 6, Santiago, Editores H. Corral y G. Acuña, 2002. BARAONA GONZÁLEZ, Jorge: "La regulación contenida en la Ley 19.496 sobre protección de los consumidores y las reglas del Código Civil y Comercial sobre contratos: un estudio comparativo". En: Revista Chilena de Derecho, Vol 41, N 2, 2014, págs. 381 y ss.

BARCIA LEHMANN, Rodrigo: Fundamentos Del Derecho de Familia y de la Infancia, Punto Lex-Thomson Reuters, Santiago, 2011.

BARRIENTOS GRANDÓN, Javier: "de la presunción general de culpa por el hecho propio. A propósito de los artículos 2314 y 2329 de nuestro 'Código Civil imaginario'. En: Revista Chilena de Derecho Privado, $\mathrm{N}^{\circ} 13$, diciembre (2009).

BARROS, Enrique: "Lo público y lo privado en el Derecho", versión revisada y completada del discurso de incorporación del autor a la Academia de Ciencias Políticas y Morales. En: Estudios Públicos, 81, (2001), págs. 5-37.

BERNASCONI, Andrés: "El carácter científico de la Dogmática”. En: Revista de Derecho (Valdivia), XX, N 1 , Junio de 2007, págs. 9-37.

BETTI, Emilio: La Interpretación jurídica, Prólogo de Guliano Crifó, (compilación y traducción de Alejandro Vergara Blanco), LexisNexis, Santiago 2006.

Revista de Ciencias Sociales - Número 66 (2015) - Universidad de Valparáíso - ISSN 0716-7725-Valparaíso, Chile 
BRAVO LIRA, Bernardino: Constitución y Reconstitución, "Historia del Estado en Iberoamérica 1511-2009", Editorial Legal Publishing Chile, Santiago, 2010.

CONTRERAS BLANCO, Oscar: La competencia desleal y el deber de corrección en la Ley chilena, Ediciones PUC, Santiago, 2012.

CORRAL, Hernán et al. Venire contra factum proprium. Escritos sobre la fundamentación, alcance y límites de la doctrina de los actos propios.

En: Cuadernos de Extensión (U. de los Andes), 18, 2010, (Hernán

Corral editor).

DEL VECCHIO, Giorgio: Los principios generales del Derecho, (prólogo de Felipe Clemente de Diego y traducción de Juan Osorio Morales), Lima, 2006.

DÍEZ-PICAZO, Luis María: La derogación de las leyes, Civitas, Madrid, 1990.

DI MAJO, Adolfo: Delle Obbligazioni en generale. En: Commentario al Codice civile, Scialoja-Branca, Zanichelli-Foro Italiano, Bologna-

Roma, 1988.

DI MAJO, Adolfo: La tutela civili dei diritti, 3, Giuffrrè, Milano, 2003.

DWORKIN, Ronald: El imperio de la justicia, Gedisa, Barcelona, 1988.

DOMINGO, Rafael y RODRÍGUEZ-ANTOLÍN, Beatriz: Aforismos Jurídicos, Aranzadi, Pamplona, 2000.

ENGISH, Karl: La idea de concreción en el derecho y en las ciencias jurídicas actuales, (estudio preliminar y traducción de Juan José

Gil Cremanes), Ediciones Universidad de Navarra, Pamplona, 1968.

GADAMER, Hans-Georg: Verdad y Método, Décimo Primera Edición, (traducción de Ana Aguad Aparicio y Rafael de Agapito), tomos

I y II, 2005.

GARCÍA AMADO, José Antonio: "Filosofía Hermenéutica y Derecho". En: http://www.uco.es/dptos/ciencias-juridicas/filosofia-derecho/ diego/Nuevo/FILOSOFIA/materiales.

GAUDEMET, Eugene: L'interprétation du Code civil en France depuis 1804, Éditions La Mémoire du Droit, Paris, 2002.

GAZMURI LARRAÍN, Daniela: El contrato como operación económica, tesis para optar al Grado de Licenciada en Derecho, U. de los Andes, Santiago de Chile, 2009.

GÉNY, Francisco: Método de Interpretación y Fuentes en el Derecho Privado Positivo, Comares, Granada, 2000.

Facultad de Derecho y Ciencias Sociales - Universidad de Valparaíso - Chile 
Metodología del derecho privado a la luz de las convenciones, tratados...

GRUNMANN, Stefan: General Clause and Standars im European Contract Law, Edited by Stefan Grunmann and Denis Mazeaud,

Kluwer Law, International, The Hague, 2006.

GORDLEY, James: The philosophical Origins of Modern Contract Doctrine, Clarendon Law Series, reimpresión, Clarendon Press, Oxford, 1991, passim.

GORDLEY, James: The jurists, Oxford, 2013.

GUZMÁN BRITO, Alejandro: "El Código Civil de Chile y sus primeros intérpretes. En: Revista Chilena de Derecho, Vol 19 N 1, 1992.

GUZMÁN BRITO, Alejandro: Las cosas incorporales en la doctrina y el derecho positivo chileno, segunda edición actualizada, Editorial Jurídica de Chile Santiago, 2006.

HART, H.L.A., The concept of law, prólogo a la segunda edición, Oxford University Press, London, 1994 (hay traducción al castellano del este prólogo en Estudios Públicos, Nº 65, 1997, págs. 226-263).

HECK, Philipp: El problema de la creación del derecho, Colofón, (versión castellana de Manuel Entenza), México DF, 1994.

HESSELINK, Martijn: "AS European Legal Method? On European Private Law and Scientific Method". En: European Law Journal,

Vol $15 \mathrm{~N}^{\circ} 1,2009$, págs. 20-45.

JHERING, Rudolph v.: El fin del Derecho, Comares, Granada, 2000.

LARENZ, Karl: Metodología de la Ciencia del Derecho, Ariel, Barcelona, 1994.

LÓPEZ SANTA MARÍA, Jorge: Los Contratos, Parte General, (quinta edición actualizada por Fabián Elorriaga De Bonis), Abeledo Perrot-Legal Publishing, Santiago, 2011.

LORENZETTI, Ricardo Luis: Razonamiento Judicial Fundamentos de Derecho Privado, IDPL- Grijley, Lima, 2006.

MARTÍNEZ DORAL: La estructura del conocimiento jurídico, Universidad de Navarra, Pamplona, 1963.

NOGUEIRA ALCALÁ, Humberto: "El valor jurídico asignado por la jurisprudencia del Tribunal Constitucional al derecho convencional internacional de los derechos humanos y su fuerza normativa en el período 2006-2013”. En: Revista Chilena de Derecho, Facultad de Derecho Pontificia Universidad Católica de Chile, Vol. 41$\mathrm{N}^{\circ}$ 2, 2014, págs. 409-435.

Revista de Ciencias Sociales - Número 66 (2015) - Universidad de Valparáíso - ISSN 0716-7725-Valparáiso, Chile 
PIMONT, Sébastien: L'economie du contract, Presses Universitaires D'Aix-Marseille-PUAM, Aix-En-Provence, 2004.

PICONTÓ NOVALES, Teresa: "Teoría general de la interpretación y hermenéutica jurídica: Betti y Gadamer”. En: Anuario de Filosofía del Derecho, IX, 1992, págs. 223 y ss.

PINOCHET OLAVE, Ruperto: "Modificación unilateral del contrato y pacto de autocontratación: dos especies de cláusulas abusivas a la luz del derecho del consumo chileno, comentario a la sentencia de la Exma. Corte Suprema de 24 de abril de 2013 recaída en el "caso Sernac con Cencosud”. En: Revista Ius et Praxis Vol.19, No 01 2013, págs. 365378.

PRADO LÓPEZ, Pamela: La colaboración del acreedor en los contratos civiles, Thomson Reuters, Santiago, 2015.

RÖDL, Florian: "Fundamental Rights, Private Law, and Societal Constitution: On the Logic of the So-Called Horizontal Effect".

En: Indiana Journal of Global Legal Studies, Vol 20, Issue No 2, 8, 2013, págs. 1015-1034.

ROMERO SEGUEL: Alejandro, La jurisprudencia de los tribunales como fuente del derecho. Una perspectiva procesal, Editorial Jurídica de Chile, Santiago, 2004.

SAN MARTÍN, Lilian: La carga del perjudicado de evitar o mitigar el daño, Universidad Externado de Colombia, Bogotá, 2012.

SANZ BAYÓN, Pablo: "Sobre la tópica jurídica en Viehweg". En: Revista Telemática de Filosofía del Derecho, No 16, 2013, págs. 83-108.

SAVIGNY, Friedrich: Metodología Jurídica, (traducción no indicada) Valletta Ediciones, Buenos Aires, 2004.

SILVA IRARRÁZAVAL, Luis Alejandro: El control de constitucionalidad de los actos administrativos legales, Legal Publishing, Santiago, 2009.

SILVA IRARRÁZAVAL, Luis Alejandro: "La dimensión legal de la interpretación constitucional". En: Revista Chilena de Derecho, Vol 41, No 2, 2014, pág. 460.

TAMAYO JARAMILLO, Javier: Manual de Hermenéutica Jurídica, Análisis constitucional, legal y jurisprudencial, Extracto adaptado y adicionado de la obra "La decisión judicial", Diké, Medellín, 2013.

VALDÉS PRIETO, Domingo: Libre Competencia y Monopolio, Editorial Jurídica de Chile, Santiago, 2009.

Facultad de Derecho y Ciencias Sociales - Universidad de Valparaíso - Chile 
VALLET DE GOYTISOLO, Juan Berchmans, Metodología de la determinación del Derecho, Editorial Centro de Estudios Ramón Areces, Madrid, 1994.

VENEGAS GRAU, María: Derechos fundamentales y Derecho privado, Marcial Pons, Madrid, 2004.

VERGARA BLANCO, Alejandro: "La Summa Divisio Iuris Público/ Privado de las disciplinas jurídicas". En: Revista de Derecho (Universidad Católica del Norte), Año 17, n 1, (2010), págs. 117 y ss.

VIGO, Rodolfo Luis: "De la interpretación de la ley y la argumentación desde la Constitución: Realidad, Teorías y valor. En: Diakaion, Año 26, Junio, $\mathrm{N}^{\circ}$ 1, 20129.

WADDAMS, STEHEN: "Protection ok weaker parties in English Law". En: Unconscionability in European Private Financial Transactions Protecting the Vulnerable, (Edited by James Devenny and Lorna Fox O’Mahony), Cambridge University Pres, 2010 (Kindle Edition), New York, pp. 26 y ss.

WEINRIB, Ernest: The idea of Private Law, Oxford University Press, 2012.

WIEACKER, Franz: Historia Moderna del Derecho Privado de la Edad Moderna, Comares, (traducción del alemán de Francisco Fernández Jardón), Granada, 2002, pág. 43.

ZAGREBELSKY, Gustavo: El derecho dúctil. Ley, derechos, justicia, (traducción de Marina Gascón, 5ª edición), Editorial Trotta, Madrid, 2003.

ZIMMERMANN, Reinhard: The law of Obligations, Roman Foundations of The Civilian Tradition, Clarendon Paperbacks, Oxford University Press, 1996. 